EXPERIMENTAL STUDY

\title{
Adipocyte-specific reduction of phosphodiesterase 3B gene expression and its restoration by JTT-501 in the obese, diabetic KKAy mouse
}

\author{
Yan Tang, Haruhiko Osawa, Hiroshi Onuma, Masaaki Hasegawa, Tatsuya Nishimiya, Masaaki Ochi and \\ Hideichi Makino \\ Department of Laboratory Medicine, Ehime University School of Medicine, Shigenobu, Ehime 791-0295, Japan \\ (Correspondence should be addressed to H Osawa; Email: harosawa@m.ehime-u.ac.jp)
}

\begin{abstract}
Objective: Phosphodiesterase (PDE) 3B is a key enzyme involved in the anti-lipolytic action of insulin in adipocytes. PDE3B activation results in a reduced output of free fatty acids (FFA), whereas elevated serum FFA is known to cause insulin resistance. We have recently reported that reduced PDE3B gene expression is restored by treatment with pioglitazone, in the adipose tissues of obese, insulin-resistant diabetic KKAy mice. To determine whether the altered PDE3B gene expression is specific for adipocytes, the expression of this gene in liver and epididymal fat tissues of KKAy mice was examined. The effect of JTT-501, another peroxisome proliferator-activated receptor (PPAR) $\gamma$ ligand, which is different from thiazolidinedione, was also examined.

Methods: PDE3B mRNA and protein were quantified by an RNase protection assay and Western blotting respectively. Membrane-bound PDE activities were also measured.

Results: In adipose tissues of KKAy mice, PDE3B mRNA, protein and membrane-bound PDE activity were reduced to $47 \%, 57 \%$ and $51 \%$ respectively relative to those in C57BL/6J control mice. JTT-501 increased PDE3B mRNA, protein and membrane-bound PDE activity by 2.2-, 1.6- and 1.7-fold respectively over those of untreated KKAy mice. In the liver, PDE3B gene expression remained unchanged in KKAy mice, and was not affected by JTT-501. JTT-501 reduced the elevated levels of serum insulin, glucose, FFA and triglyceride in KKAy mice.

Conclusions: PDE3B gene expression was specifically reduced in the adipose tissues of KKAy mice. JTT-501 restored this reduced gene expression with an accompanying improvement in elevated serum FFA and insulin resistance.
\end{abstract}

European Journal of Endocrinology 145 93-99

\section{Introduction}

Eleven different gene families which involve mammalian cyclic nucleotide phosphodiesterase (PDE1 to 11) have been reported to date (1). PDE3B represents a major isoform of PDE in adipocytes. Insulin exerts its antilipolytic action via the phosphorylation and subsequent activation of PDE3B. The activation of this enzyme is accompanied by a decrease in intracellular cAMP which, in turn, leads to a reduction in cAMP-dependent protein kinase A (PKA) activity. This subsequently leads to the dephosphorylation and inactivation of hormone-sensitive lipase (HSL), leading to a decreased rate of hydrolysis of stored triglycerides and, as a result, to a reduction in the release of free fatty acids (FFA) from adipocytes $(2,3)$.

PDE3B is also thought to be the major, insulinactivated isoform of PDE in the liver (4). Glucagon and insulin, two antagonistic hormones, are the most important glucoregulatory factors in the liver. Glucagon exerts its effect by enhancing the cAMP-PKA pathway, while insulin inhibits the effect of glucagon (5). The effect of insulin on glycogen synthesis and glycogenolysis is mediated, at least in part, by the enhancement of PDE, which inhibits the cAMP-PKA pathway (6-8). A reduction in the intracellular concentration of cAMP by insulin results in an increase in the rate of synthesis of fatty acids and triglycerides, as well as glycogen in this tissue $(9,10)$.

Type 2 diabetes mellitus is clinically characterized by insulin resistance in target tissues, which include adipose tissue, skeletal muscle and liver (11). It is possible that a reduced insulin sensitivity in adipocytes represents an event which occurs prior to overt insulin resistance in such tissues (12). When the antilipolytic action of insulin is inhibited, the rate of release of FFA from triglycerides is increased. It is well known that an elevation in serum FFA leads directly to insulin resistance in skeletal muscle and liver, as well as adipose tissues (13). 
In prior studies, we were able to demonstrate that basal and insulin-induced membrane-bound PDE (mainly PDE3B) activities are impaired in the epididymal adipocytes of insulin-resistant diabetic KK mice, spontaneously obese rats and dexamethasone-treated rats (14-16). Other studies have also concluded that PDE activity is reduced in the adipocytes of diabetic patients or rats $(17,18)$. Nagaoka et al. have also shown that PDE3B mRNA is reduced in obese diabetic $c p / c p$ rats (19). More recently, we demonstrated that PDE3B gene expression is reduced in the adipocytes of obese, insulin-resistant, diabetic KKAy mice. Treatment with pioglitazone, an insulin-sensitizing thiazolidinedione, restores this altered PDE3B gene expression with a parallel improvement in insulin resistance (20). However, the issues of whether this alteration of PDE3B gene expression is specific for adipocytes and whether insulin-sensitizing compounds generally affect PDE3B gene expression have not yet been examined.

In view of this, we initiated an analysis of PDE3B gene expression in liver as well as the epididymal fat tissues of KKAy mice. Our findings show that steadystate membrane-bound PDE activity, PDE3B protein or the corresponding mRNA levels are reduced only in the adipose tissues of these mice. Treatment with an isoxazolidinedione, JTT-501 $(21,22)$, a peroxisome proliferator-activated receptor (PPAR) $\gamma$ ligand that is different from thiazolidinedione, restores all these parameters in parallel with an improvement in hyperglycemia, elevated FFA and insulin resistance.

\section{Materials and methods}

\section{Animals and tissue preparation}

Male non-diabetic C57BL/6J mice and insulin-resistant KKAy mice were purchased from Clea Japan (Osaka, Japan) and were used experimentally when they reached an age of 10-11 weeks. KKAy mice are the result of a cross between glucose-intolerant black KK female mice and yellow male obese Ay mice, and are known to serve as excellent models of obese insulinresistant type 2 diabetes (23). C57BL/6J mice were generally employed as controls for KKAy mice (20). The mice were housed individually, and were provided with food and water and allowed to feed ad libitum. The treatment group of KKAy mice received JTT-501 in their food at a level of $0.18 \%$ (from Japan Tobacco Inc., Osaka, Japan), which resulted in the overall ingestion of $300 \mathrm{mg} / \mathrm{kg}$ per day over a 4-day period. The mice were killed by rapid decapitation under light diethyl ether anesthesia and the epididymal fat tissues and liver were removed rapidly. For the RNase protection assay, the tissues were homogenized with TRI REAGENT LS (Molecular Research Center Inc., Cincinnati, OH, USA), frozen in liquid nitrogen, and then stored at $-80{ }^{\circ} \mathrm{C}$. For Western blotting, fat and liver tissues were homogenized with STS buffer $(250 \mathrm{mM}$ sucrose,
$10 \mathrm{mM}$ N-tris(hydroxymethyl)methyl-2-aminoethanesulfonic acid, $15 \mu \mathrm{g} / \mathrm{ml}$ pepstatine, $15 \mu \mathrm{g} / \mathrm{ml}$ leupeptine, $3 \mathrm{mM}$ benzamidine, $0.5 \mathrm{mM}$ phenylmethylsulfonyl fluoride, $\mathrm{pH}$ 7.0). For the assay of membrane-bound PDE activity, the liver was homogenized as described above, and free adipocytes were prepared from fresh fat tissues by the collagenase method (24). Blood samples were also collected when killed. Serum glucose, FFA, triglycerides and insulin were determined using previously described methods (20). All experimental procedures were approved by the Animal Experimentation Committee of Ehime University, School of Medicine.

\section{RNase protection assay}

Total RNA was isolated from liver and adipose tissues that had been homogenized in TRI REAGENT LS according to the manufacturer's instructions (Molecular Research Center Inc.). The integrity of each RNA sample was confirmed by intact $18 \mathrm{~S}$ and $28 \mathrm{~S}$ rRNA, which was stained with ethidium bromide on an agarose gel. The concentration and purity was assessed by absorbance at $260 \mathrm{~nm}$ and by the $260 / 280 \mathrm{~nm}$ ratio respectively.

RNase protection assay (RPA) was carried out as previously described (20). A 449 nt biotinylated cRNA probe which contained a $395 \mathrm{nt}$ antisense mouse PDE3B RNA was transcribed using a MAXIscript In Vitro Transcription T7 Kit (Ambion, Austin, TX, USA) and Biotin-16-UTP (Boehringer Mannheim Corporation, Indianapolis, IN, USA). A $300 \mathrm{nt}$ biotinylated RNA probe, which contained a 250 nt mouse $\beta$-actin antisense RNA, and RNA molecular markers were also produced using the pTRI- $\beta$-actin-mouse control template DNA and the RNA Century Marker Template Set respectively (Ambion). HybSpeed RPA (Ambion) was used to hybridize the purified cRNA probes of PDE3B and $\beta$-actin with $10 \mu \mathrm{g}$ of each total RNA which had been extracted from liver and adipose tissues. The protected RNAs were separated by 5\% acrylamide$8 \mathrm{~mol} / \mathrm{l}$ urea gel electrophoresis, transferred to a Brightstar-Plus positively charged nylon membrane and were then visualized by the Brightstar BioDetect Kit (Ambion). The cRNAs, which were detected by chemiluminescence, were exposed and quantitated using 1D Image Analysis Software (Kodak Digital Science, Kodak, Rochester, NY, USA). Since the protected PDE3B and $\beta$-actin RNAs are of different sizes (395 and $250 \mathrm{nt}$ respectively), both RNA species could be quantitated in a single RNA sample. The $\mathrm{PDE} 3 \mathrm{~B} / \beta$-actin mRNA ratio was calculated and the mean value in $\mathrm{C} 57 \mathrm{BL} / 6 \mathrm{~J}$ mice defined as 1 -fold. We were able to confirm that $\beta$-actin mRNA could be used to correct the PDE3B mRNA in each sample from liver as well (C57BL, $1.00 \pm 0.06$; KKAy, $1.03 \pm 0.07 ; \quad$ JTT-KKAy, $1.01 \pm 0.03 ; n=6$ ), as shown in the case of adipose tissue (20). 


\section{Western blotting}

Adipose and liver tissues were homogenized directly with STS buffer. In order to examine the difference between KKAy and C57BL mice, adipocytes were isolated from fresh epididymal fat tissues and were then homogenized in STS buffer, and the membranebound fraction was obtained as described previously $(25,26)$. Aliquots of protein samples $(20 \mu \mathrm{g}$ each $)$ were electrophoresed on $7.5 \%$ polyacrylamide gels and the resulting size-fractionated proteins were electrophoretically transferred to Immobilon membranes (Millipore, Bedford, MA, USA). These membranes were incubated with an anti-rat PDE3B polyclonal antibody raised in rabbits against the $\mathrm{NH}_{2}$-terminal peptide (amino acid residues 1-17) (20). Visualization of the PDE3B protein was carried out with an enhanced chemiluminescence detection system as described previously (20). The autographs were quantitatively analyzed by 1D Image Analysis Software (Kodak Digital Science). The specificity of our anti-rat PDE3B polyclonal antibody was confirmed by pre-incubating the antibody with the $\mathrm{NH}_{2}$-terminus peptide (amino acids 1 to 17 ) of rat PDE3B as a competitor, as described previously (20).

\section{Membrane-bound PDE (mainly PDE3B) catalytic activity}

Membrane-bound PDE activity was assayed exactly as described previously $(25,26)$. Briefly, isolated adipocytes, epididymal fat pads, or liver were homogenized with STS buffer, the membrane-bound fraction was then suspended in pH 7.5 STS buffer, and the PDE activity was subsequently determined.

\section{Statistical analysis}

An unpaired Student's $t$-test was used for all the experiments, and results are expressed as means \pm s.E.s. $P<0.05$ was taken as significant.

\section{Results}

\section{Effect of JTT-501 on serum insulin, glucose, triglyceride and FFA levels in KKAy mice}

We first compared body weight, epididymal fat pad weight, serum glucose, FFA, triglyceride and insulin concentrations of the KKAy mice to those of the control C57BL/6J mice (Table 1). The KKAy mice were obese, hyperinsulinemic, hyperglycemic and hyperlipidemic compared with the controls. A 4-day treatment with JTT-501 resulted in a reduction in serum glucose, FFA, triglycerides and insulin levels in the KKAy mice. The JTT-501-treated KKAy mice showed a slight increase (about 10\%) in body weight and epididymal fat pad weight relative to the untreated KKAy mice.

\section{Effect of JTT-501 on PDE3B mRNA in adipose tissues and liver of KKAy mice}

To determine whether PDE3B mRNA is altered in KKAy mice, adipose tissue and liver PDE3B mRNA were compared with those of control C57BL mice using RPA (Fig. 1). The sizes of the protected probes were exactly the same, as expected, thus enabling us to determine PDE3B mRNA, as described previously (20). In the adipose tissue of the KKAy mice, the level of PDE3B mRNA was $47 \%$ that of the control mice (control $1.00 \pm 0.08$ vs KKAy $0.47 \pm 0.03$ fold induction, $n=6$, $P<0.01)$. JTT-501 treatment restored this reduced level of PDE3B mRNA to the same as that in control C57BL mice (JTT-KKAy $1.01 \pm 0.07$ fold induction, $n=6 . P<0.01$ ) (Fig. 1A). This increase was significant when compared with that of untreated KKAy mice. In the liver of the KKAy mice, the level of PDE3B mRNA was the same as that of the control mice (control $1.00 \pm 0.07$ vs KKAy $0.92 \pm 0.05$ fold induction, $n=6$ ). JTT-501 had no effect on PDE3B mRNA levels in this tissue in KKAy mice (JTT-501-treated KKAy $0.99 \pm 0.08, n=6$ ) (Fig. 1B). Thus, steady-state PDE3B mRNA was decreased in the adipose tissues but was not affected in the liver of KKAy mice. Treatment with JTT-501 restored the levels of this reduced PDE3B mRNA in adipose tissues, but had no effect on the levels in the liver.

\section{Effect of JTT-501 on PDE3B protein in adipose tissues and liver of KKAy mice}

To examine whether the changes in PDE3B mRNA levels of the above-mentioned KKAy mice were accompanied by a corresponding change in the level

Table 1 The effect of JTT-501 on body and epididymal fat pad weight, serum glucose levels, FFA, triglycerides and insulin concentrations in KKAy mice.

\begin{tabular}{|c|c|c|c|c|c|c|c|}
\hline Experimental groups & $n$ & $\begin{array}{l}\text { Body weight } \\
\text { (g) }\end{array}$ & $\begin{array}{l}\text { Epididymal fat } \\
\text { pad weight }(\mathrm{g})\end{array}$ & $\begin{array}{c}\text { Glucose } \\
\text { (mg/dl) }\end{array}$ & $\begin{array}{c}\text { FFA } \\
(\mathrm{mEq} / \mathrm{l})\end{array}$ & $\begin{array}{l}\text { Triglycerides } \\
\text { (mg/dl) }\end{array}$ & $\begin{array}{l}\text { Insulin } \\
\text { (ng/ml) }\end{array}$ \\
\hline C57BL/6J mice & 6 & $27.5 \pm 0.3$ & $0.46 \pm 0.02$ & $231 \pm 5$ & $0.30 \pm 0.02$ & $79 \pm 5$ & $0.5 \pm 0.0$ \\
\hline Untreated KKAy mice & 8 & $41.8 \pm 0.6$ & $1.72 \pm 0.07$ & $700 \pm 46^{a}$ & $1.68 \pm 0.07^{\mathrm{a}}$ & $592 \pm 77^{a}$ & $51.7 \pm 5.7^{\mathrm{a}}$ \\
\hline JTT-KKAy mice & 8 & $45.2 \pm 0.8^{b}$ & $1.89 \pm 0.03$ & $438 \pm 40^{b}$ & $0.58 \pm 0.04^{b}$ & $116 \pm 12^{b}$ & $24.2 \pm 7.0^{b}$ \\
\hline
\end{tabular}

Data are the means \pm S.E.S. ${ }^{a}$ Significant differences compared with $\mathrm{C} 57$ mice, $P<0.01$. ${ }^{\mathrm{b}}$ Significant differences compared with untreated KKAy mice, $P<0.01$. JTT-KKAy: JTT-501-treated KKAy mice. 

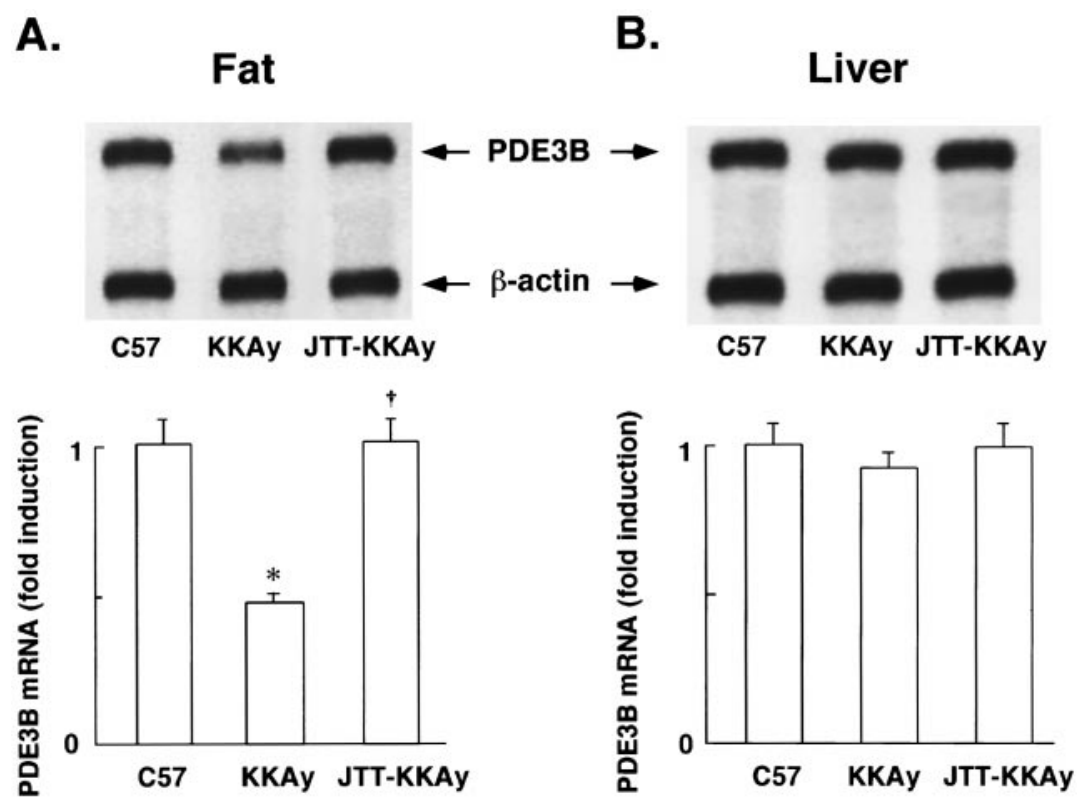

Figure 1 Effect of JTT-501 on PDE3B mRNA
in (A) adipose tissues and (B) liver of KKAy
mice. PDE3B mRNA was measured by RPA
in epididymal fat tissues and liver from C57BL/
$6 \mathrm{~J}$ control, KKAy and JTT-501-treated KKAy
mice, as described in the Materials and
methods section. The mice $(n=6$ in each
experimental group) were $10-11$ weeks old.
JTT-501 ( 300 mg/kg per day) was adminis-
tered for a period of 4 days in the case of the
treated KKAy mice. The 395 nt PDE3B
protected probes and the 250 nt protected
$\beta$-actin probes are shown in the upper
panel. PDE3B mRNA is expressed as the
intensity of the protected PDE3B band
corrected by that of the protected $\beta$-actin
band in each lane. The mean value in the
untreated db/+ mice is then defined as 1.00
and the magnitude of the induction is shown
as the mean \pm S.E. (fold) in the lower panel.
* Significant difference compared with
C57BL/6J mice $(P<0.01)$. + Significant
difference compared with untreated
KKAy mice $(P<0.01)$. JTT-KKAy: JTT-501-
treated KKAy mice.

of PDE3B protein, we next assessed the steady-state PDE3B protein by Western blotting using the specific PDE3B antibody as described previously (20) (Fig. 2). It has been confirmed that this antibody is specific to PDE3B in the liver as well as adipose tissue by incubation with the $\mathrm{NH}_{2}$-terminus peptide (1 to 17 aa) of rat $\mathrm{PDE} 3 \mathrm{~B}$ as a competitor (data not shown). The level of PDE3B protein in adipose tissue of KKAy mice was $57 \%$ that of the control mice (control $1.00 \pm 0.05$, vs KKAy $0.57 \pm 0.03$ fold, $n=6, P<0.01)$. JTT-501 treatment restored this reduced level of PDE3B protein to a level which was nearly the same that in the control C57BL mice (JTT-KKAy $0.91 \pm 0.08$ fold, $n=6$. $P<0.01$ ) (Fig. 2A). This increase was also significant when compared with that of untreated KKAy mice. No significant difference in the level of PDE3B protein from the liver of KKAy and C57 mice (control 1.00 \pm 0.07 vs KKAy $0.89 \pm 0.04$ fold, $n=6$ ) were detected. JTT501 had no effect on PDE3B protein levels in this tissue (JTT-KKAy $1.01 \pm 0.08$ fold, $n=6$ ) (Fig. 2B). Thus, steady-state PDE3B protein was decreased in the adipose tissues but was not affected in the liver of KKAy mice. JTT-501 treatment restored this reduced PDE3B protein in adipose tissues but had no effect on that in the liver.

\section{Effect of JTT-501 on membrane-bound PDE activities in adipose tissues and liver of KKAy mice}

As a final output of PDE3B gene expression, the membrane-bound PDE (mainly PDE3B) activity was measured (Fig. 3). The activity in adipocytes was decreased in KKAy mice (control C57BL $105.6 \pm 1.8$ vs KKAy $53.6 \pm 2.5 \mathrm{pmol} / \mathrm{mg}$ per min, $n=6, P<0.01)$ and was restored by treatment with JTT-501 (JTT-KKAy $89.2 \pm 9.3 \mathrm{pmol} / \mathrm{mg}$ per $\min , n=6$, $P<0.01$ ) (Fig. 3A). In the liver of untreated KKAy mice, the membrane-bound PDE activity was not affected compared with that of the control mice (control C57BL 20.5 \pm 0.6 vs KKAy $19.9 \pm$ $2.3 \mathrm{pmol} / \mathrm{mg}$ per min, $n=8)$. JTT-501 had no effect on this activity (JTT-KKAy $20.8 \pm 1.5 \mathrm{pmol} / \mathrm{mg}$ per min, $n=6$ ) (Fig. 3B). Thus, the membrane-bound PDE activity, and the levels of either steady-state protein or mRNA were decreased in adipose tissues but remained unchanged in the liver in KKAy mice. Treatment with JTT-501 restored all these parameters in adipose tissues but had no effect on those in the liver, in parallel with an improvement in hyperglycemia, elevated FFA and insulin resistance.

\section{Discussion}

The data herein show that PDE3B gene expression is reduced in adipocytes, but not in the liver of obese, insulin-resistant, diabetic KKAy mice. This reduced PDE3B gene expression in adipose tissue is restored by treatment with JTT-501, which is correlated with an improvement in elevated serum FFA and insulin resistance. The expression of this gene in the liver was not affected, suggesting that the altered gene expression in adipocytes is specific.

As well as thiazolidinediones, an isoxazolidinedione, JTT-501, is also a ligand for PPAR $\gamma(21)$. In fat tissues, adipogenesis is stimulated via the activation of PPAR $\gamma$ by ligands (27). Two types of thiazolidinediones, troglitazone and pioglitazone, cause an increase in the number of small adipocytes, which is probably the result of the induction of adipocyte differentiation 
A. Fat
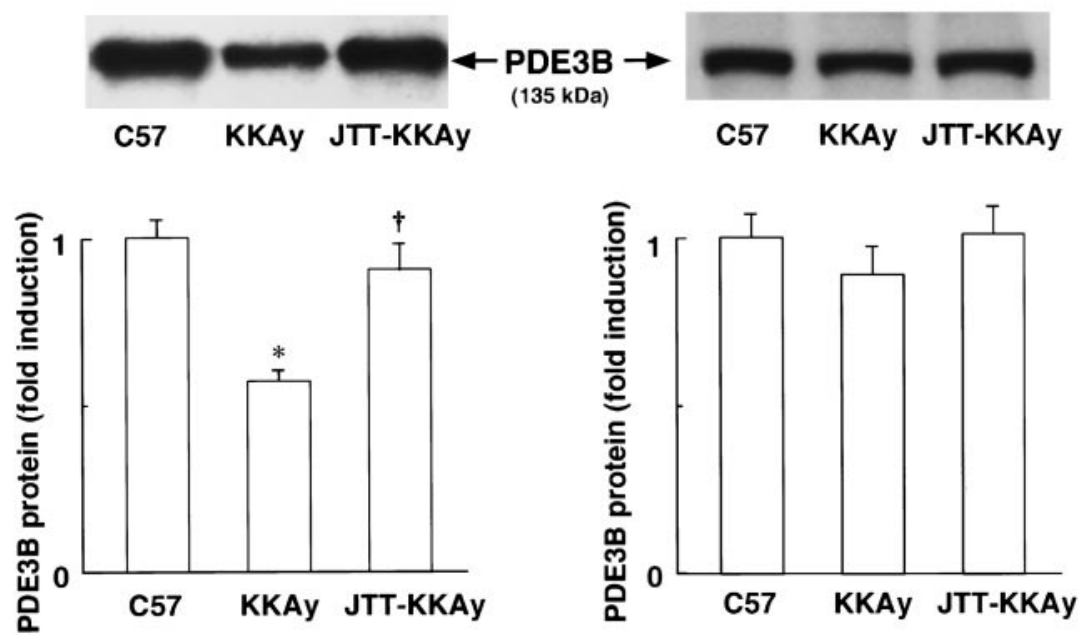

B.

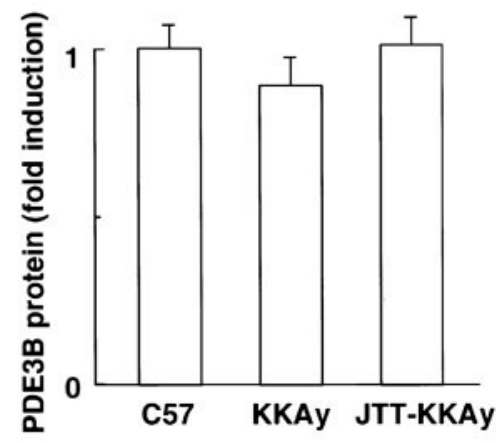

Figure 2 Effect of JTT-501 on PDE3B protein in (A) adipose tissues and (B) liver of KKAy mice. Western blotting was carried out using the anti-PDE3B antibody raised against the $\mathrm{N}$ terminal peptide $(1-17)$ of rat PDE3B as described in Materials and methods. All mice were 10-11 weeks old. JTT-501 (300 mg/kg per day) was administrated for 4 days in the case of the treated KKAy mice. The specific $135 \mathrm{kDa}$ PDE3B bands from the adipose tissue and liver are shown in the upper panel. The mean value of PDE3B protein intensity in the adipose tissues and liver of the C57BL/6J mice is defined as 1.00 and the fold induction is shown as mean \pm S.E. (fold) in the lower panel. *Significant difference compared with C57BL/6J mice $(P<0.01, n=4)$. †Significant difference compared with untreated KKAy mice $(P<0.01, n=4)$. JTT-KKAy: JTT-501-treated KKAy mice.
(28, 29). PDE3B mRNA levels are also increased during differentiation from pre-adipocyte to adipocytes in 3T3-L1 cells (30). Therefore, it is possible that the effect of JTT-501 on PDE3B gene expression, as demonstrated in the present study, is related to the differentiation state of the adipocytes. PPAR $\gamma$ is mainly expressed in adipose tissues, whereas PPAR $\alpha$ is mainly expressed in the liver. This could account for the difference in regulation in PDE3B gene expression by JTT-501 for the liver vis-à-vis adipose tissue $(31,32)$.

An enlargement of adipocytes and an increase in fat mass are some of the characteristics of obesity (33). The basal and catecholamine-stimulated rate of lipolysis as well as intracellular cAMP concentration and HSL activity is positively correlated with fat cell size (34-36). In fact, both the level of lipolysis and that of circulating FFA are increased in obese humans and animals $(37,38)$. It is possible that the inactivation of PDE3B results in an increase in HSL activity, which, in turn, would lead to an enhanced rate of release of FFA. Thus, a reduction in PDE3B gene expression in the adipocytes of KKAy mice could contribute to an increase in the rate of FFA release.

The PDE3B gene expression was reduced in adipose tissues of polygenic obese insulin-resistant models, KKAy mice, and was restored by JTT-501. This result is consistent with that found for $\mathrm{db} / \mathrm{db}$ mice, the monogenic obese insulin-resistant models, due to an abnormality in the leptin receptor (39). Thus, the reduced PDE3B gene expression in adipocytes could represent the common event in insulin resistance which is observed in these obese insulin-resistant diabetic mice regardless of their genetic backgrounds (20). The restoration of this reduced gene expression in adipose tissue by three types of PPAR $\gamma$ ligands, namely JTT-501, pioglitazone and troglitazone (39), with a paralleled improvement in insulin resistance, further supports this hypothesis. Likewise, in human obese type 2 diabetes mellitus, the reduced PDE3B gene expression in adipocytes could account for the development of insulin resistance.

In summary, PDE3B gene expression is reduced in adipocytes but remains unchanged in the liver of KKAy
A.

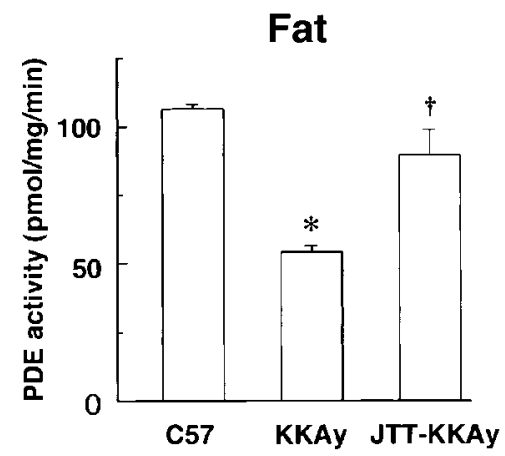

B.

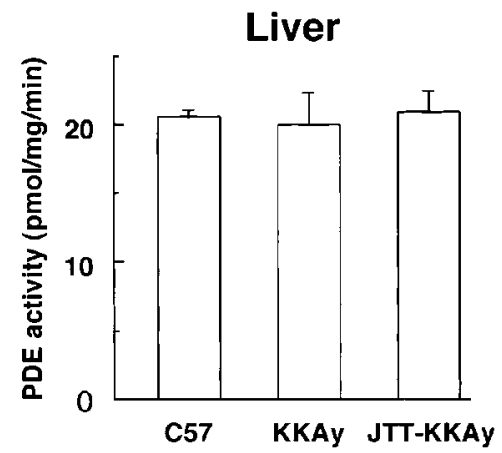

Figure 3 Effect of JTT-501 on membrane-bound PDE (mainly PDE3B) activity in the (A) adipose tissues and (B) liver of KKAy mice. All mice were 10-11 weeks old. JTT-501 (300 mg/kg per day) was administrated for 4 days in the case of the treated KKAy mice. The membrane-bound PDE activity was determined in the epididymal adipocytes and liver of C57BL/6J control mice, KKAy mice and JTT-501-treated KKAy mice as described in the Materials and methods section. Columns represent means \pm s.E.S of PDE catalytic activity (pmol/mg per min). *Significant difference compared with C57BL/6J control mice $(P<0.01$, $n=8)$. †Significant difference compared with untreated KKAy mice $(P<0.01, n=6)$. JTT-KKAy: JTT-501-treated KKAy mice. 
Obese Insulin Resistant Mice Adipocyte

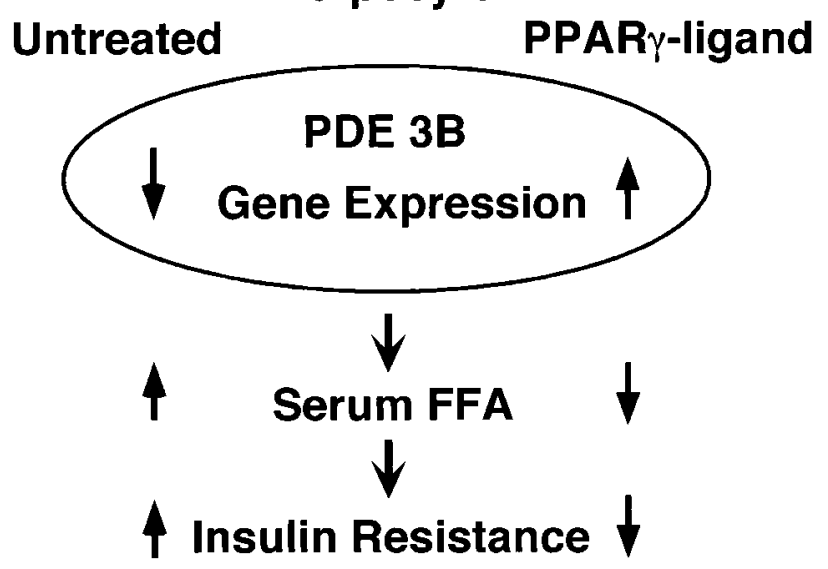

Figure $4 \mathrm{~A}$ possible role of PDE3B gene expression in insulin resistance. PDE3B mediates antilypolytic action of insulin and the activation of PDE3B results in reduced FFA output from adipocytes. An elevation in serum FFA is known to cause insulin resistance in the skeletal muscle and liver and, of these insulin target tissues, adipocytes are the most sensitive to insulin. PDE3B gene expression is reduced specifically in adipose tissue of obese, insulin-resistant rodents. This reduced gene expression could cause insulin resistance through elevated serum FFA. PPARy ligands such as JTT-501 increase PDE3B gene expression in adipocytes, which could improve insulin resistance through the reduction of serum FFA.

mice (Fig. 4). JTT-501 restores this altered gene expression only in adipocytes with an accompanying improvement in insulin resistance. The issue of how PDE3B gene expression is regulated under these conditions, and whether the altered PDE3B gene expression is the primary cause of insulin resistance observed with human obese type 2 diabetes is not presently clear. These topics merit further investigation.

\section{Acknowledgements}

This work was supported by Grant-in-Aid for Scientific Research on Priority Areas (C) from the Ministry of Education, Science, Sports and Culture (no. 12204007), Grant-in-Aid for Scientific Research (C) from the Japanese Society for the Promotion of Science (nos 11671122 and 11671124), Japan Tobacco Inc., Miura Educational Foundation, Sasakawa Health Science Foundation, Charitable Trust Clinical Pathology Research Foundation in Japan, and Ehime Health Foundation. We thank Drs Okukawa, S Masuda, T Yagi and M Murase for technical assistance and suggestions.

\section{References}

1 Francis SH, Turko IV \& Corbin JD. Cyclic nucleotide phosphodiesterases: relating structure and function. Progress in Nucleic Acid Research and Molecular Biology 200065 1-52.
2 Makino H, Suzuki T, Kajinuma H, Yamazaki M, Ito H \& Yoshida S. The role of insulin-sensitive phosphodiesterase in insulin action. Advances in Second Messenger and Phosphoprotein Research 1992 25 185-189.

3 Carey GB. Mechanisms regulating adipocyte lipolysis. Advances in Experimental Medicine and Biology $1998 \mathbf{4 4 1}$ 157-170.

4 Reinhardt RR, Chin E, Zhou J, Taira M, Murata T \& Manganiello VC. Distinctive anatomical patterns of gene expression for cGMP-inhibited cyclic nucleotide phosphodiesterases. Journal of Clinical Investigation 199595 1528-1538 [Published erratum appears in Journal of Clinical Investigation 199799 551].

5 Unger RH \& Foster DW. Diabetes mellitus. In Williams Textbook of Endocrinology, edn 9, ch 21, pp 1002-1003. Eds JD Wilson, DW Foster, HM Kronenberg \& PR Larson. Philadelphia: W.B. Saunders, 1998.

6 Pilkis SJ, Claus TH \& el-Maghrabi MR. The role of cyclic AMP in rapid and long-term regulation of gluconeogenesis and glycolysis. Advances in Second Messenger and Phosphoprotein Research 198822 175-191.

7 Beebe SJ, Redmon JB, Blackmore PF \& Corbin JD. Discriminative insulin antagonism of stimulatory effects of various cAMP analogs on adipocyte lipolysis and hepatocyte glycogenolysis. Journal of Biological Chemistry $198526015781-15788$.

8 Hermsdorf T \& Dettmer D. Combined effects of insulin and dexamethasone on cyclic AMP phosphodiesterase 3 and glycogen metabolism in cultured rat hepatocytes. Cellular Signalling 1998 10 629-635.

9 Paulauskis JD \& Sul HS. Cloning and expression of mouse fatty acid synthase and other specific mRNAs. Developmental and hormonal regulation in 3T3-L1 cells. Journal of Biological Chemistry 1988263 7049-7054.

10 Ochs RS \& Harris RA. Glucagon and N6,O2'-dibutyryl adenosine $3^{\prime}: 5^{\prime}$-monophosphate inhibition of lipogenesis and phosphofructokinase activity of hepatocytes from meal-fed rats. Lipids 198015 504-511.

11 DeFronzo RA, Bonadonna RC \& Ferrannini E. Pathogenesis of NIDDM. A balanced overview. Diabetes Care 199215 318368.

12 McGarry JD. What if Minkowski had been ageusic? An alternative angle on diabetes. Science 1992258 766-770.

13 Boden G. Role of fatty acids in the pathogenesis of insulin resistance and NIDDM. [Published erratum appears in Diabetes 199746 536] Diabetes 199746 3-10.

14 Makino H, Kanatsuka A, Suzuki T, Kuribayashi S, Hashimoto N, Yoshida S et al. Insulin resistance of fat cells from spontaneously diabetic KK mice. Analysis of insulin-sensitive phosphodiesterase. Diabetes 198534 844-849.

15 Osegawa M, Makino H, Kanatsuka A, Suzuki T \& Yoshida S. Effects of changes in serum insulin in response to dexamethasone and adrenalectomy on insulin-sensitive phosphodiesterase in rat fat cells. Metabolism 198433 754-759.

16 Suzuki T, Makino H, Kanatsuka A, Kuribayashi S, Hashimoto N \& Yoshida S. Insulin-sensitive phosphodiesterase and insulin receptor binding in fat cells from spontaneously obese rats. Diabetologia 198528 286-290.

17 Engfeldt P, Arner P, Bolinder J \& Ostman J. Phosphodiesterase activity in human subcutaneous adipose tissue in insulin- and noninsulin-dependent diabetes mellitus. Journal of Clinical Endocrinology and Metabolism 198255 983-988.

18 Solomon SS. Effect of insulin and lipolytic hormones on cyclic AMP phosphodiesterase activity in normal and diabetic rat adipose tissue. Endocrinology 197596 1366-1373.

19 Nagaoka T, Shirakawa T, Balon TW, Russell JC \& FujitaYamaguchi Y. Cyclic nucleotide phosphodiesterase 3 expression in vivo: evidence for tissue-specific expression of phosphodiesterase $3 \mathrm{~A}$ or $3 \mathrm{~B}$ mRNA and activity in the aorta and adipose tissue of atherosclerosis-prone insulin-resistant rats. Diabetes $1998 \mathbf{4 7}$ $1135-1144$. 
20 Tang Y, Osawa H, Onuma H, Nishimiya T, Ochi M \& Makino H. Improvement in insulin resistance and the restoration of reduced phosphodiesterase $3 \mathrm{~B}$ gene expression by pioglitazone in adipose tissue of obese diabetic KKAy mice. Diabetes $1999 \mathbf{4 8} 1830$ 1835.

21 Shibata T, Matsui K, Nagao K, Shinkai H, Yonemori F \& Wakitani K. Pharmacological profiles of a novel oral antidiabetic agent, JTT-501, an isoxazolidinedione derivative. European Journal of Pharmacology 1999364 211-219.

22 Terasaki J, Anai M, Funaki M, Shibata T, Inukai K, Ogihara T et al. Role of JTT-501, a new insulin sensitiser, in restoring impaired GLUT4 translocation in adipocytes of rats fed a high fat diet. Diabetologia 199841 400-409.

23 Chang AY, Wyse BM, Copeland EJ, Peterson T \& Ledbetter SR. The Upjohn colony of KKAy mice: a model for obese type II diabetes. In Diabetes, pp 466-470. Eds M Serrano-Rios \& PJ Lefebvre. Amsterdam: Elsevier, 1986.

24 Rodbell M. Metabolism of isolated fat cells. Journal of Biological Chemistry 1964239 375-380.

25 Makino H, de Buschiazzo PM, Pointer RH, Jordan JE \& Kono T. Characterization of insulin-sensitive phosphodiesterase in fat cells. I. Effects of salts and oxidation-reduction agents. Journal of Biological Chemistry 1980255 7845-7849.

26 Onuma $H$, Makino $H$, Osawa H, Suzuki Y, Taira M, Kanatsuka A et al. Mitogen-activated protein kinase and p70 ribosomal protein S6 kinase are not involved in the insulindependent stimulation of cAMP phosphodiesterase kinase in rat adipocytes. Biochimica et Biophysica Acta $19981402197-$ 208.

27 Spiegelman BM. PPAR-gamma: adipogenic regulator and thiazolidinedione receptor. Diabetes $1998 \mathbf{4 7} 507-514$.

28 Okuno A, Tamemoto H, Tobe K, Ueki K, Mori Y, Iwamoto K et al. Troglitazone increases the number of small adipocytes without the change of white adipose tissue mass in obese Zucker rats. Journal of Clinical Investigation $1998 \mathbf{1 0 1} 1354-1361$.

29 Hallakou S, Doare L, Foufelle F, Kergoat M, Guerre-Millo M, Berthault MF et al. Pioglitazone induces in vivo adipocyte differentiation in the obese Zucker fa/fa rat. Diabetes $1997 \mathbf{4 6}$ 1393-1399.

30 Taira M, Hockman SC, Calvo JC, Belfrage P \& Manganiello VC. Molecular cloning of the rat adipocyte hormone-sensitive cyclic
GMP-inhibited cyclic nucleotide phosphodiesterase. Journal of Biological Chemistry 1993268 18573-18579.

31 Tontonoz P, Hu E \& Spiegelman BM. Stimulation of adipogenesis in fibroblasts by PPAR gamma 2, a lipid-activated transcription factor. Cell 1994 79 1147-1156 [Published erratum appears in Cell $1995 \mathbf{8 0} 957]$.

32 Braissant O, Foufelle F, Scotto C, Dauca M \& Wahli W. Differential expression of peroxisome proliferator-activated receptors (PPARs): tissue distribution of PPAR-alpha, -beta, and -gamma in the adult rat. Endocrinology $1996137354-$ 366.

33 Crandall DL, Goldstein BM, Huggins F \& Cervoni P. Adipocyte blood flow: influence of age, anatomic location, and dietary manipulation. American Journal of Physiology 1984247 R46R51.

34 Berger JJ \& Barnard RJ. Effect of diet on fat cell size and hormonesensitive lipase activity. Journal of Applied Physiology 199987 227-232.

35 Arner P \& Ostman J. Relationship between the tissue level of cyclic AMP and the fat cell size of human adipose tissue. Journal of Lipid Research 197819 613-618.

36 Reynisdottir S, Dauzats M, Thorne A \& Langin D. Comparison of hormone-sensitive lipase activity in visceral and subcutaneous human adipose tissue. Journal of Clinical Endocrinology and Metabolism 199782 4162-4166.

37 Robinson C, Tamborlane WV, Maggs DG, Enoksson S, Sherwin RS, Silver D et al. Effect of insulin on glycerol production in obese adolescents. American Journal of Physiology 1998274 E737-E743.

38 Fujiwara T, Yoshioka S, Yoshioka T, Ushiyama I \& Horikoshi H. Characterization of new oral antidiabetic agent CS-Studies in KK and ob/ob mice and Zucker fatty rats. Diabetes 1988371549 1558 .

39 Osawa H, Tang Y, Onuma H, Nishimiya T, Ochi M, Hasegawa M et al. Phosphodiesterase $3 \mathrm{~B}$ gene expression is enhanced in the liver but reduced in the adipose tissue of obese insulin resistant $\mathrm{db} / \mathrm{db}$ mouse. Diabetes 200049 A288.

Received 4 July 2000

Accepted 19 March 2001 